\title{
Hydroxychloroquine and Covid-19: A Cellular and Molecular Biology Based Update
}

\author{
Amit Pal $^{1} \cdot$ Anil Pawar $^{2} \cdot$ Kalyan Goswami $^{1} \cdot$ Praveen Sharma $^{3} \cdot$ Rajendra Prasad $^{4}(\mathbb{C}$
}

Received: 22 May 2020/Accepted: 3 June 2020/Published online: 10 June 2020

(C) Association of Clinical Biochemists of India 2020

\begin{abstract}
As the time for finding a definitive and safe cure as a vaccine for novel Corona Virus Disease 2019 (Covid19) is still far, there is need to study in depth about the other potential drugs, which can save millions of lives due to Covid-19 pandemic. Right at the center of the debate is the use of drug "Hydroxychloroquine" as a prophylaxis as well as a treatment strategy against Covid-19 in conjunction with azithromycin. In this review, we will study the cellular and molecular aspects of hydroxychloroquine, which had driven its use in Covid-19 patients, as well as its chemistry and pharmacokinetics along with clinical trials going on worldwide using hydroxychloroquine against Covid-19.
\end{abstract}

Keywords Covid-19 - Hydroxychloroquine - Cytokine storm $\cdot$ Severe acute respiratory syndrome coronavirus 2

Amit Pal and Anil Pawar: co-first authors.

Amit Pal and Anil Pawar have contributed equally to this work.

Electronic supplementary material The online version of this article (https://doi.org/10.1007/s12291-020-00900-x) contains supplementary material, which is available to authorized users.

Rajendra Prasad

fateh1977@yahoo.com

1 Department of Biochemistry, AIIMS, Kalyani 741235, West Bengal, India

2 Department of Zoology, DAV University, Jalandhar 144012, Punjab, India

3 Department of Biochemistry, AIIMS, Jodhpur 342005, Rajasthan, India

4 Department of Biochemistry, MM Institute of Medical Sciences and Research, Mullana, Ambala 133207, Haryana, India

\section{Introduction}

Without a therapeutic vaccine or specific antiviral drugs, and with a desperate attempt to find a cure against novel Corona Virus Disease 2019 (Covid-19) [1], the limelight was shifted to hydoxychloroquine (derivative of chloroquine that has antimalarial, antiinflammatory, immunosuppressive and antiautophagy activities [2,3]; upon a tweet by US president Mr. Donald J. Trump. On 21st March, 2020, he tweeted, "Hydroxychloroquine and Azithromycin, taken together, have a real chance to be one of the biggest game changers in the history of medicine" (https://twitter.com/realdonaldtrump/status/ 1241367239900778501?lang=en).

However, easier said than done, initial studies of Covid19 patients treated with hydoxychloroquine with or without azithromycin were shown to have mixed results, with more scrutiny being raised over the lack of proper design of these studies. Without clinical trials and robust methodologically correct scientific studies there is skepticism over benefits and efficacy of hydoxychloroquine against Covid-19. Till the writing of this article, as per the information available on NCBI, currently worldwide 1450 clinical trials are going on (https://clinicaltrials.gov/ct2/results?cond $=\%$ 22 wuhan+coronavirus\%22) and 180 different compounds are being tested against Covid-19 (https://pubchem.ncbi. nlm.nih.gov/\#tab=compound \&query $=$ covid $-19 \%$

20clinicaltrials).

Though the exact mechanisms are still unclear; however, it has been established from scientific literature that at the molecular level, hydroxychloroquine affects the activity of lysosomes and in turn autophagy and disrupts lysosomal membrane stability. Also, it alters the transcriptional activity and signaling pathways. At the cellular level also, the precise mode of action of hydroxychloroquine is yet to 
be delineated. Based upon current understanding, hydroxychloroquine has been shown to inhibit immune system activation. Suppression of immune system activation by hydroxychloroquine is achieved by reducing cytokine production and Toll-like receptor (TLR) signaling pathways $[2,3]$.

The main aim of this review is to discuss the mode of action of hydroxychloroquine at cellular and molecular levels, that potentially support the clinical efficacy and few adverse side effects observed in Covid-19 patients treated with hydroxychloroquine, which may further help in improving the clinical outcomes by modifying or altering the drug itself or its restricted use in certain individuals by enforcing strict inclusion and exclusion criteria. The readers are referred to more holistic review for clinical use of hydroxychloroquine in other diseases like rheumatoid arthritis, systemic lupus erythematosus, antiphospholipid syndrome and primary Sjögren syndrome [2, 3].

\section{Covid-19}

Towards the end of year 2019 (December, 2019), Chinese Province of Wuhan reported the emergence of Covid-19 in humans characterized with atypical pneumonia, fever, dry cough and progressive dyspnea [4]. Novel coronavirus 2019 (nCoV-2019), officially known as severe acute respiratory syndrome coronavirus 2 (SARS-CoV-2), was demonstrated to cause Covid-19 [5]. Within a span of around 3 months, Covid-19 spread worldwide forcing the World Health Organization (WHO) to declare it as pandemic on 11th March 2020. As per the WHO-Covid-19 dashboard available at https://covid19.who.int/, as of 31st May, 2020, there have been 5,939,234 confirmed cases of Covid-19, including 367,255 deaths worldwide. It is now well established that respiratory transmission and direct contact transmission are the main routes for Covid-19 transmission. Previously, Coronaviruses (CoVs) also have been responsible for the severe acute respiratory syndrome (SARS) and Middle East respiratory syndrome (MERS) outbreaks. [6, 7].

\section{Clinical Features and Laboratory Diagnosis of Covid-19}

According to Centers for Disease Control and Prevention (CDC), USA (available at https://www.cdc.gov/cor onavirus/2019-ncov/symptoms-testing/symptoms.html)

and recent literature, Covid-19 infected people demonstrate a wide range of symptoms-ranging from mild symptoms to severe illness. Most common symptoms of confirmed positive Covid-19 patients were fever, cough, shortness of breath, myalgia or fatigue and sore throat; whereas, headache, chills, new loss of taste or smell, sputum production, diarrhea, and vomiting like symptoms may also occur [8-12].

Elderly people and people, who have severe underlying medical conditions, seem to be at higher risk for developing more serious complications from COVID-19 compared to young healthy adults $[9,10,13,14]$. Most of deaths due to Covid-19 were due to severe respiratory failure, pneumonia and multiple organ failure [10].

Initially, a combination of computed tomography (CT) imaging, electron microscopy, and whole genome sequencing were used to screen and identify SARS-CoV-2 [4, 15-19]. Confirmatory diagnosis of Covid-19 relies on the real-time reverse transcriptase-polymerase chain reaction (RT-PCR) method. RNA-dependent RNA polymerase (RdRp) gene of the ORF1ab sequence, E gene, $\mathrm{N}$ gene, and $\mathrm{S}$ gene of the SARS-CoV-2 genome is the basis of RT-PCR tests for the diagnosis of SARS-CoV-2 $[4,15,16]$.

Among the laboratory parameters, most moderate Covid-19 patient's exhibited leucopenia, lymphopenia, high level of C-reactive protein (CRP) and erythrocyte sedimentation rate $[12,20]$. However, severe Covid-19 patients showed frequent lymphopenia, with increased levels of lactate dehydrogenase, CRP, ferritin, alanine aminotransferase, and D-dimer along with grossly higher levels of interleukins (ILs) IL-2R, IL-6, IL-10, and Tumor necrosis factor- $\alpha[9,12,14,20]$. Acute respiratory distress syndrome (ARDS) and multiple-organ failure in Covid-19 are thought to result from "Cytokine storm" also known as cytokine release syndrome. "Cytokine storm" is an excessive immune response to an external stimulus. "Cytokine storm" in severe Covid-19 cases, if left untreated for a longer time, results in an increased risk of vascular hyperpermeability, multiorgan failure, and eventually death [21, 22]. Due to observance of Cytokine storm in severe Covid-19 cases; some authors have suggested theoretical treatment strategies like use of IL-6 and IL-1 family antagonists, TNF blockers and corticosteroid therapy among other strategies [22, 23].

\section{Hydroxychloroquine: Structure and Its Chemistry}

Hydroxychloroquine, (PubChem CID: 3652, https://pub chem.ncbi.nlm.nih.gov/compound/3652, Molecular formula: $\mathrm{C}_{18} \mathrm{H}_{26} \mathrm{ClN}_{3} \mathrm{O}$ ) also known as Plaquenil, Oxichloroquine, Oxychlorochin, is a derivative of chloroquine exhibiting immunosuppressive, anti-inflammatory, antiautophagy, and antimalarial activities. Due to these properties, hydroxychloroquine is now most often used as an antirheumatologic agent in systemic lupus erythematosis and rheumatoid arthritis. This is the reason that both 
hydroxychloroquine and chloroquine are classified under Disease-modifying antirheumatic drugs (DMARDs). Hydroxychloroquine is derived from chloroquine, and differ from it by the presence of a hydroxyl group. Both hydroxychloroquine and chloroquine are weak bases, and a half-life of around 50 days. Hydroxychloroquine and chloroquine belong to 4-aminoquinolines drugs class (reviewed in [3].

\section{Pharmacokinetics of Hydroxychloroquine}

As chloroquine and hydroxychloroquine have almost similar structure and mode of action, both drugs can be used against SARS-CoV-1 and SARS-CoV-2 [24, 25]. As compared to chloroquine, hydroxychloroquine is a better therapeutic agent in terms of safety index. Various modes of action have been postulated to explain the therapeutic uses of hydroxychloroquine, but most of them are based on in vitro studies (reviewed in [3]). Hydroxychloroquine, which is administered as hydroxychloroquine sulfate, has a lag time of $0-0.85 \mathrm{~h}$ for $200 \mathrm{mg}$ salt. It is the time between oral absorption and its measurement in the blood. It is usually absorbed in the upper intestinal region [26] and has an overall bioavailability of $0.7-0.8$. The concentration of hydroxychloroquine can vary not only in plasma, blood and serum of individual patient but also among different patients [27]. It is intriguing to note that hydroxychloroquine has a half-life period of approximately 1-2 months and the mean residence time of nearly $1300 \mathrm{~h}$ [28].

\section{Mode of Action of Hydroxychloroquine}

The precise mechanism of action of hydroxychloroquine is not known till date, and there is lots of research going on the existing knowledge gap using diverse advanced scientific tools like [3] Computational biology [29], Immunology [30, 31], Structural biology [32, 33], Modern molecular medicine [34, 35], Synthetic biology [36, 37], and 'big data'-driven public health science [38, 39].

Hydroxychloroquine may suppress immune function by interfering with the processing and presentation of antigens, and the production of cytokines. Acidic vesicles, such as endosomes/lysosomes, which are essential for the membrane fusion, act as major locations of action of chloroquine and hydroxychloroquine [2, 3, 40]. Chloroquine accumulates in lysosomes (lysosomotropism), and by increasing their $\mathrm{pH}$, interferes with the glycosylation of cellular receptor of SARS-CoV-2 and thereby inhibits the infection of virus [14, 40]. An important feature of hydroxychloroquine is its capability to inhibit the innate as well as acquired immunity [41]. Hydroxychloroquine may also affect signaling of TLR receptors by changing the endosomal $\mathrm{pH}$ [42] as well as by inhibiting TLR-ligand interactions. Further research is required to know the exact mechanism by which this drug affects TLR activation.

Additionally, hydroxychloroquine by interfering the lysosomal activity and autophagy, inhibits the antigen processing and presentation along with MHC-II molecules and subsequently immune system activation. Reduced activation of $\mathrm{CD} 4{ }^{+} \mathrm{T}$ cells leads to decreased production of proinflammatory markers and cytokines [14, 40]. It has been suggested that autophagy is involved in autoantigen presentation mediated by MHC class II molecules, and activation of T-helper cells [43]. Because of immunomodulatory and anti-inflammatory properties, hydroxychloroquine can prove to be a better remedy for SARS-CoV-2 patients, where cytokine storm has emerged as a potentially fatal condition [12, 22].

As an anti-inflammatory agent, hydroxychloroquine is also used to treat various autoimmune disorders such as rheumatoid arthritis, systemic lupus erythematosus and Sjogren's syndrome [3, 5]. Hydroxychloroquine also exhibits antibacterial property particularly against intracellular bacteria such as Coxiella burnetii [44]. However, due to strong affinity of hydroxychloroquine for melanin, it can deposit in tissues such as the skin and the eyes (hydroxychloroquine retinopathy) [3].

Hydroxychloroquine is thought to prevent the thrombotic complications by behaving like anticoagulant agents, and hence can prove beneficial for cases with a secondary coagulopathy owing to systemic inflammation [45]. This is done most probably by inhibiting the platelet aggregation [46, 47] or inhibition of binding of antiphospholipid antibody in autoinflammatory diseases [48]. Hydroxychloroquine is found to be safe to use during pregnancy and various studies have shown that it checks the initiation of congenital heart blockage $[49,50]$, possibly by reducing the expression of a type I interferon (IFN) signature [51].

\section{Hydroxychloroquine interaction with other drugs}

During combination therapy, hydroxychloroquine may interfere the functioning of other drugs or vice versa because it is metabolized by the same enzyme cytochrome P450 (CYP), which is responsible for the metabolism of many other drugs [3, 27, 52, 53]. Hydroxychloroquine increases the bioavailability of metoprolol in blood plasma by reducing its metabolism. Although similar effect is not observed for drugs, such as dextromethorphan [54] and methotrexate [55]. On the other hand, bioavailability of hydroxychloroquine may be affected by the medicines that increase the $\mathrm{pH}$ of gastric juice [3]. Hydroxychloroquine 
can also interfere with drugs that affect the QT interval; hence possibility of cardiac arrhythmia should be checked in such patients $[56,57]$. Combination therapy of breast cancer using tamoxifen and hydroxychloroquine may cause eye toxicity due to synergistic inhibition of enzymes in lysosomes of retinal epithelial cells [58]. Thus, duration of such therapy should be monitored carefully. Some of the adverse outcomes of hydroxychloroquine usage are gastrointestinal effects, including nausea, vomiting, diarrhea and abdominal discomfort [59]. Moreover, Hydroxychloroquine-associated cardiotoxic effects including rhythm disorders and cardiomyopathy in rheumatic patients have also been reported [57,60].

\section{Hydroxychloroquine and Covid-19}

Hydroxychloroquine has attracted attention over the past few decades as a potential antiviral agent, and currently as a possible treatment for Covid-19 [40, 61, 62]. However, whether hydroxychloroquine works in vivo against Covid19 remains to be seen conclusively. The word of caution is that in randomized controlled trials against a number of viruses, including influenza, hydroxychloroquine haven't work at all. Hydroxychloroquine is known to decrease the acidity in endosomes, which in turn might avert the endosome from releasing the virus into the cytoplasm. Biggest limitation is the lack of preclinical data for hydroxychloroquine against Covid-19 and its repeated failure against most viral diseases under in vivo conditions [61].

Another issue with hydroxychloroquine is adverse outcomes in certain patients with comorbid conditions who are on other medications [40, 61, 62]. It has been reported that hydroxychloroquine can also interfere with drugs that affect the QT interval [57]. One concern in the Covid-19 patients receiving hydroxychloroquine/chloroquine \pm azithromycin is the prolongation of QT interval, which may possibly increase the risk of Torsade de pointes (TdP; [63]) and sudden cardiac death. A prospective observational study of large cohort of COVID-19 patients treated with chloroquine/hydroxychloroquine \pm azithromycin has demonstrated no instances of TdP or arrhythmogenic death. Even though, it was shown that use of these medications resulted in QT prolongation [64].

Due to its cellular and molecular effects as discussed in previous sections, quite a few clinical trials are studying the effectiveness and safety of hydroxychloroquine (also chloroquine) for Covid-19 (https://clinicaltrials.gov/ct2/ results?cond $=\% 22$ wuhan + coronavirus $\% 22$ ). Upon searching for interventional studies among clinical trials against Covid-19, till the writing of this article we (authors) have found 885 interventional studies using various drugs. Among these 885 studies, 51 studies were found to be using hydroxychloroquine alone (Table 1) and 104 studies are using hydroxychloroquine in combination with other antiviral/nutritional supplements/probiotics etc. (Supplementary material 1). Most of the studies for hydroxychloroquine against Covid-19 are focussing on its safety and efficacy as well its use as a prophylaxis measure against Covid-19 (Table 1). Few of these clinical trials are also evaluating optimal hydroxychloroquine dose, and its use in moderate and severe Covid-19 cases, and pregnant Covid-19 positive women (Table 1). Seven clinical trial registries were also found in Chinese Clinical Trial Registry (http://www.chictr.org.cn) for using hydoxychloroquine to treat Covid-19 [5].

In a recent significant development (on May 22nd, 2020), an observational study published in Lancet journal reported that hydroxychloroquine or chloroquine, when used alone or with macrolide, on in-hospital outcomes for Covid-19 were associated with decreased in-hospital survival along with an increased frequency of ventricular arrhythmias [65]. Acting swiftly on this report on May 27th, 2020, WHO executive group implemented a temporary pause of the hydroxychloroquine arm within the Solidarity Trial while the safety data is reviewed by the Data Safety Monitoring Board (https://www.who.int/emergen cies/diseases/novel-coronavirus-2019/global-research-onnovel-coronavirus-2019-ncov/solidarity-clinical-trial-forcovid-19-treatments). Expressing shock over this move by WHO, various eminent scientists ( $>140$ scientists) have written an open letter to Editor of Lancet journal and authors of the study about their concerns over data integrity, plenty of loopholes and erroneous conclusions in the study among host of other concerns (https://www.tropi calmedicine.ox.ac.uk/news/an-open-letter-to-richard-hor ton-editor-of-the-lancet-regarding-mehra-etal).

However, Indian Council of Medical Research (ICMR), New Delhi, India has maintained its earlier guidelines on use of hydroxychloroquine as prophylaxis for SARS-CoV2 infection (https://www.mohfw.gov.in/pdf/Advisor yontheuseofHydroxychloroquina

sprophylaxisforSARSCoV2infection.pdf) in its revised guidelines too (https://www.icmr.gov.in/pdf/covid/techdoc/ V5_Revised_advisory_on_the_use_of_HCQ_SARS_

CoV2_infection.pdf). In its revised guidelines published on 22nd May, 2020, ICMR has expanded to include following personnel for use of hydroxychloroquine as prophylaxis for SARS-CoV-2 infection (1) All asymptomatic healthcare workers working in Covid hospital/non-Covid hospitals/ non-Covid areas of Covid hospitals/blocks (2) Asymptomatic frontline workers/paramilitary/police personnel working in Covid-19 containment zones, and (3) 
Table 1 Clinical trials with hydroxychloroquine alone

\begin{tabular}{|c|c|c|}
\hline $\begin{array}{l}\text { S. Clinical trial study title } \\
\text { no. }\end{array}$ & Intervention (drug/s) & $\begin{array}{l}\text { Weblink to clinical } \\
\text { trial }\end{array}$ \\
\hline
\end{tabular}

Hydroxychloroquine as prophylaxis drug against Covid-19

1 Prophylaxis for Patients at Risk of COVID-19 infection

Drug: Hydroxychloroquine Sulfate 200 MG

2 Hydroxychloroquine Chemoprophylaxis in Healthcare Personnel in Contact With COVID-19 Patients (PHYDRA Trial)

3 Randomized, Controlled, Double-blind Clinical Trial Comparing the Efficacy and Safety of Chemoprophylaxis With Hydroxychloroquine in Patients Under Biological Treatment and/or JAK Inhibitors in the Prevention of SARS-CoV-2 Infection

4 PRophylaxis of Exposed COVID-19 Individuals With Mild Symptoms Using choloroquinE Compounds

5 PROLIFIC ChemoprophylaxisTrial (COVID-19)

6 Immune Monitoring of Prophylactic Effect of Hydroxychloroquine in Healthcare Providers Highly Exposed to COVID-19

7 Pre-exposure Prophylaxis for SARS-Coronavirus-2

8 Post-Exposure Prophylaxis for Asymptomatic SARS-CoV2 COVID-19 Patients With choloroquine Compounds

9 Hydroxychloroquine as Prophylaxis for COVID-19 in Healthcare Workers (HCQPreP)

10 Assessment of the Efficacy and Safety of (HCQ) as a Prophylaxis for COVID19 for Health Professionals

11 Protect: Study With Hydroxychloroquine for Prevention and Early Phase Treatment of Coronavirus Disease (COVID-19)

12 HEalth Care Worker pROphylaxis Against COVID-19: The HERO Trial

13 Hydroxychloroquine as Chemoprevention for COVID-19 for High Risk Healthcare Workers

14 Hydroxychloroquine Post Exposure Prophylaxis for Coronavirus Disease (COVID-19)
Drug: HydroxychloroquinelDrug: Placebo oral tablet

Drug: HidroxicloroquinalDrug: Control group

Drug: Hydroxychloroquine Sulfate Regular doselDrug:

Hydroxychloroquine Sulfate Loading DoselDrug:

ChloroquinelDrug: Placebo

Drug: Hydroxychloroquine-Daily dosingIDrug:

Hydroxychloroquine-Weekly DosinglOther: Matched

Placebo Hydroxychloroquine

Drug: HydroxychloroquinelDrug: Placebo oral tablet

Drug: HydroxychloroquinelOther: Placebo

Drug: Hydroxychloroquine Sulfate Regular doselDrug: Hydroxychloroquine Sulfate Loading DoselDrug: ChloroquinelDrug: Placebo

Drug: HydroxychloroquinelDrug: Placebo

Drug: Hydroxychloroquine (HCQ)|Drug: Placebo oral tablet

Drug: Hydroxychloroquine

Drug: Hydroxychloroquine Pre-Exposure

ProphylaxislDrug: Placebo oral tablet

Drug: Hydroxychloroquine Sulfate (HCQ)

Drug: HydroxychloroquinelDrug: Placebo oral tablet https://

ClinicalTrials. gov/show/ NCT04389359

https:// ClinicalTrials. gov/show/ NCT04318015

https:// ClinicalTrials. gov/show/ NCT04330495

https://

ClinicalTrials. gov/show/ NCT04351191

https:// clinicaltrials. gov/show/ NCT04352933

https:// ClinicalTrials. gov/show/ NCT04346329

https:// ClinicalTrials. gov/show/ NCT04328467

https://

ClinicalTrials. gov/show/ NCT04346667

https:// ClinicalTrials. gov/show/ NCT04363450

https://

ClinicalTrials. gov/show/ NCT04349228

https://

ClinicalTrials. gov/show/ NCT04363827

https://

ClinicalTrials. gov/show/ NCT04352946

https://

ClinicalTrials. gov/show/ NCT04345653

https://

ClinicalTrials. 
Table 1 continued

S. Clinical trial study title Intervention (drug/s)

no.

15 Pre-Exposure Prophylaxis With Hydroxychloroquine for High-Risk Healthcare Workers During the COVID-19 Pandemic

16 Prophylactic Benefit of Hydroxychloroquine in COVID-19 Drug: Hydroxychloroquine Sulfate Cases With Mild to Moderate Symptoms and in Healthcare Workers With High Exposure Risk

17 Hydroxychloroquine Chemoprophylaxis for COVID-19 Infection in High-risk Healthcare Workers.

18 Hydroxychloroquine as Post Exposure Prophylaxis for SARS-CoV-2(HOPE Trial)

19 Does Hydroxychloroquine Before \& During Patient Exposure Protect Healthcare Workers From Coronavirus?

20 Hydroxychloroquine to Prevent COVID-19 Disease Amongst Healthcare Workers

21 Hydroxychloroquine Versus Placebo in COVID-19 Patients at Risk for Severe Disease

Clinical trials on safety and efficacy of Hydroxychloroquine against Covid-19

22 The PATCH Trial (Prevention And Treatment of COVID19 With Hydroxychloroquine)

23 ALBERTA HOPE COVID-19 for the Prevention of Severe COVID19 Disease

24 Hydroxychloroquine in SARS-CoV-2 (COVID-19) Pneumonia Trial

25 A Pilot Study to Assess Hydroxychloroquine in Patients With SARS-CoV-2 (COVID-19)

26 COVID-19 PrEP HCW HCQ

27 Hydroxychloroquine in the Prevention of COVID-19 Infection in Healthcare Workers

28 Norwegian Coronavirus Disease 2019 Study
Drug: HydroxychloroquinelDrug: Placebos

Drug: HydroxychloroquinelDrug: Placebo oral tablet

Drug: Hydroxychloroquine as post exposure prophylaxis|

Drug: HydroxychloroquinelDrug: Placebo oral tablet

Drug: Apo-HydroxychloroquinelDrug: Matched Placebo

Drug: HydroxychloroquinelDrug: Placebo
Weblink to clinical trial

gov/show/

NCT04318444

https://

ClinicalTrials. gov/show/ NCT04331834

https://

ClinicalTrials. gov/show/ NCT04371926

https://

ClinicalTrials. gov/show/ NCT04370015

https://

ClinicalTrials. gov/show/ NCT04330144

https://

ClinicalTrials. gov/show/ NCT04374942

https://

clinicaltrials. gov/show/ NCT04371523

https:// clinicaltrials. gov/show/ NCT04325893

https://

ClinicalTrials. gov/show/ NCT04329923 . Hydroxychloroquine a daylDrug: Hydroxychloroquine Sulfate $600 \mathrm{mg}$ once a daylDrug: Placebo oral tablet

Drug: Hydroxychloroquine

https://

ClinicalTrials. gov/show/ NCT04329611

https://

clinicaltrials. gov/show/ NCT04382625

Drug: HydroxychloroquinelDrug: Placebo

https://

clinicaltrials. gov/show/ NCT04363866

https://

ClinicalTrials. gov/show/ NCT04354870

Drug: Hydroxychloroquine

https://

ClinicalTrials. gov/show/ NCT04333225

https:// ClinicalTrials. 
Table 1 continued

S. Clinical trial study title

no.

29 Will Hydroxychloroquine Impede or Prevent COVID-19

30 A Study of Hydroxycholoroquine Compared to Placebo as Treatment for People With COVID-19

31 Efficacy and Safety of Hydroxychloroquine for Treatment of COVID-19

32 Chloroquine/Hydroxychloroquine Prevention of Coronavirus Disease (COVID-19) in the Healthcare Setting

33 PATCH 2\&3:Prevention \& Treatment of COVID-19 (Severe Acute Respiratory Syndrome Coronavirus 2) With Hydroxychloroquine

34 Hydroxychloroquine Treatment of Healthcare Workers With COVID19 Illness at Montefiore

35 Healthcare Worker Exposure Response and Outcomes of Hydroxychloroquine

36 Safety And Efficacy Of Hydroxychloroquine For At Risk Population (SHARP) Against COVID-19

37 University of Utah COVID-19 Hydrochloroquine Trial

38 Outcomes Related to COVID-19 Treated With Hydroxychloroquine Among In-patients With Symptomatic Disease

39 Chloroquine Outpatient Treatment Evaluation for HIVCovid-19

40 A Randomized Controlled Clinical Trial:

Hydroxychloroquine for the Treatment of COVID-19 in Hospitalized Patients

41 Trial of Hydroxychloroquine In Covid-19

42 Hydroxychloroquine for COVID-19
Intervention (drug/s)

Drug: Hydroxychloroquine-Daily Dosing|Drug: Hydroxychloroquine-Weekly DosinglOther: Placebo oral

Drug: HydroxychloroquinelOther: Placebo

Drug: Hydroxychloroquine

Drug: Chloroquine or HydroxychloroquinelDrug: Placebo

Drug: Group A HCQIDrug: Group B Control

Drug: Hydroxychloroquine

Drug: HydroxychloroquinelDrug: Placebo oral tablet

Drug: Hydroxychloroquine Sulfate 200 mg (mg) Tab

Drug: HydroxychloroquinelDrug: Placebo oral tablet

Drug: HydroxychloroquinelDrug: Placebo

Drug: Chloroquine or hydroxychloroquine

Drug: Hydroxychloroquine

Drug: HydroxychloroquinelOther: Placebo

Drug: Hydroxychloroquine SulfatelDrug: Placebo
Weblink to clinical trial

gov/show/

NCT04316377

https://

ClinicalTrials. gov/show/

NCT04341441

https://

ClinicalTrials. gov/show/

NCT04379492

https://

ClinicalTrials. gov/show/

NCT04261517

https://

ClinicalTrials. gov/show/ NCT04303507

https://

ClinicalTrials. gov/show/ NCT04353037

https://

ClinicalTrials. gov/show/ NCT04350450

https://

ClinicalTrials. gov/show/ NCT04334148

https://

ClinicalTrials. gov/show/ NCT04342156

https://

ClinicalTrials. gov/show/ NCT04342169

https://

ClinicalTrials. gov/show/ NCT04332991

https://

ClinicalTrials. gov/show/ NCT04360759

https://

ClinicalTrials. gov/show/ NCT04345692

https://

ClinicalTrials. gov/show/ NCT04353271

https:// ClinicalTrials. gov/show/ NCT04342221 
Table 1 continued

\begin{tabular}{|c|c|c|c|}
\hline $\begin{array}{l}\text { S. } \\
\text { no. }\end{array}$ & Clinical trial study title & Intervention (drug/s) & $\begin{array}{l}\text { Weblink to clinical } \\
\text { trial }\end{array}$ \\
\hline 43 & $\begin{array}{l}\text { Efficacy and Tolerability of Hydroxychloroquine in Adult } \\
\text { Patients With COVID-19 }\end{array}$ & Drug: Hydroxychloroquine Sulfate 200 MG [Plaquenil] & $\begin{array}{l}\text { https:// } \\
\text { ClinicalTrials. } \\
\text { gov/show/ } \\
\text { NCT04384380 }\end{array}$ \\
\hline \multicolumn{4}{|c|}{ Clinical trials of Hydroxychloroquine as per severity of Covid-19 } \\
\hline 44 & $\begin{array}{l}\text { Hydroxychloroquine for the Treatment of Mild COVID-19 } \\
\text { Disease }\end{array}$ & Drug: HydroxychloroquinelDrug: Placebo & $\begin{array}{l}\text { https:// } \\
\text { ClinicalTrials. } \\
\text { gov/show/ } \\
\text { NCT04340544 }\end{array}$ \\
\hline 45 & $\begin{array}{l}\text { Chloroquine, Hydroxychloroquine or Only Supportive } \\
\text { Care in Patients AdmItted With Moderate to Severe } \\
\text { COVID-19 }\end{array}$ & $\begin{array}{l}\text { Drug: Chloroquine SulfatelDrug: } \\
\text { HydroxychloroquinelOther: Standard supportive care }\end{array}$ & $\begin{array}{l}\text { https:// } \\
\text { ClinicalTrials. } \\
\text { gov/show/ } \\
\text { NCT04362332 }\end{array}$ \\
\hline 46 & $\begin{array}{l}\text { Hydroxychloroquine Treatment for Severe COVID-19 } \\
\text { Pulmonary Infection (HYDRA Trial) }\end{array}$ & Drug: HydroxychloroquinelDrug: Placebo oral tablet & $\begin{array}{l}\text { https:// } \\
\text { ClinicalTrials. } \\
\text { gov/show/ } \\
\text { NCT04315896 }\end{array}$ \\
\hline 47 & $\begin{array}{l}\text { Hydroxychloroquine for the Treatment of Patients With } \\
\text { Mild to Moderate COVID-19 to Prevent Progression to } \\
\text { Severe Infection or Death }\end{array}$ & $\begin{array}{l}\text { Drug: HydroxychloroquinelOther: The control group } \\
\text { will not receive hydroxychloroquine }\end{array}$ & $\begin{array}{l}\text { https:// } \\
\text { ClinicalTrials. } \\
\text { gov/show/ } \\
\text { NCT04323631 }\end{array}$ \\
\hline \multicolumn{4}{|c|}{ Clinical trials focusing on dose of Hydroxychloroquine against Covid-19 } \\
\hline 48 & $\begin{array}{l}\text { High-dose Hydroxychloroquine for the Treatment of } \\
\text { Ambulatory Patients With Mild COVID-19 }\end{array}$ & Drug: Hydroxychloroquine & $\begin{array}{l}\text { https:// } \\
\text { ClinicalTrials. } \\
\text { gov/show/ } \\
\text { NCT04351620 }\end{array}$ \\
\hline 49 & $\begin{array}{l}\text { Efficacy of Various Doses of Hydroxychloroquine in Pre- } \\
\text { Exposure Prophylaxis for COVID } 19\end{array}$ & $\begin{array}{l}\text { Drug: Hydroxychloroquine Sulfate } 200 \text { MG|Other: } \\
\text { Placebo }\end{array}$ & $\begin{array}{l}\text { https:// } \\
\text { ClinicalTrials. } \\
\text { gov/show/ } \\
\text { NCT04359537 }\end{array}$ \\
\hline \multicolumn{4}{|c|}{ Clinical trials on effect of Hydroxychloroquine in COVID-19 Positive Pregnant Women } \\
\hline 50 & $\begin{array}{l}\text { Effect of Hydroxychloroquine in COVID-19 Positive } \\
\text { Pregnant Women }\end{array}$ & $\begin{array}{l}\text { Drug: hydroxychloroquine sulfate } 200 \text { MGIDrug: } \\
\text { Placebo oral tablet }\end{array}$ & $\begin{array}{l}\text { https:// } \\
\text { ClinicalTrials. } \\
\text { gov/show/ } \\
\text { NCT04354441 }\end{array}$ \\
\hline \multicolumn{4}{|c|}{ Clinical trial for Hydroxychloroquine in Elderly positive Covid-19 people of age $>65$ years } \\
\hline 51 & Test and Treat COVID 65plus + & Drug: HydroxychloroquinelOther: Placebo & $\begin{array}{l}\text { https:// } \\
\text { ClinicalTrials. } \\
\text { gov/show/ } \\
\text { NCT04351516 }\end{array}$ \\
\hline
\end{tabular}

$H C Q$ Hydroxychloroquine

Asymptomatic household contacts of laboratory confirmed Covid-19 cases.

\section{Summary and Future Directions}

Covid-19, caused by SARS-CoV-2, had become a pandemic and public health concern considering health and economy related challenges to combat and contain this disease. Due to sudden emergence of Covid-19, the healthcare system was caught unaware without an effective and safe treatment for this infectious disease. Chloroquine 
and hydroxychloroquine both are weak bases that tend to accumulate in acidic compartments such as lysosomes and inflamed (acidic) tissues. By raising the intra-lysosomal $\mathrm{pH}$, hydroxychloroquine impairs the autophagic protein degradation [3].

More studies are required to understand the concentration, distribution and effects of hydroxychloroquine in various tissues, as well as interrelationship between given dose and response generated. Identification of exact molecular targets of hydroxychloroquine within the cell as well as on different microbes is the need of hour. More importantly, efficacy of anti-malarial compounds, other than chloroquine and hydroxychloroquine, should be monitored against SARS-CoV including SARS-CoV-2. Newer compounds closely mimicking the hydroxychloroquine like hydroxyferrochloroquine have been synthesized in past, and have shown to exert antiviral effects with some selectivity toward SARS-CoV infection [25]. This approach can be further exploited and/or reinforced to make newer compound with less toxicity and greater selectivity towards SARS-CoV-2.

There are reports of high risk of thrombosis in patients with severe SARS-CoV-2 infection [66] and procoagulant pattern of patients with COVID-19 ARDS justify the clinical reports of thromboembolic complications (pulmonary embolism) during the course of the Covid-19 [67]. Interestingly, hydroxychloroquine has been associated with reduced risk of thrombosis in several in vitro and animal studies. Potential mechanisms by which hydroxychloroquine and chloroquine reduce the procoagulatory state in autoinflammatory diseases include inhibition of antiphospholipid antibody binding [48] or inhibition of platelet aggregation [46, 47, 68]. Notably, in a mouse model of antiphospholipid syndrome, hydroxychloroquine treatment was associated with improvement in endothelial function $[69,70]$. The exact molecular mechanisms by which DMARD hydroxychloroquine drug mediate their antithrombotic effects remain largely unknown and lay the platform for future prospective studies.

Acknowledgements Authors duly acknowledge the CDC, NCBI, $\mathrm{NIH}$ and WHO for providing free online clinical trials/research articles/information pertaining to Covid-19.

\section{Compliance with Ethical Standards}

Conflict of interest The authors declare that they have no conflict of interest.

\section{References}

1. Zhu N, Zhang D, Wang W, Li X, Yang B, Song J, et al. A novel coronavirus from patients with pneumonia in China, 2019. N Engl J Med. 2020;382(8):727-33.

2. Rainsford KD, Parke AL, Clifford-Rashotte M, Kean WF. Therapy and pharmacological properties of hydroxychloroquine and chloroquine in treatment of systemic lupus erythematosus, rheumatoid arthritis and related diseases. Inflammopharmacology. 2015;23:231-69.

3. Schrezenmeier E, Dorner T. Mechanisms of action of hydroxychloroquine and chloroquine: implications for rheumatology. Nat Rev Rheumatol. 2020;16:155-66.

4. Xu X, Yu C, Qu J, Zhang L, Jiang S, Huang D, et al. Imaging and clinical features of patients with 2019 novel coronavirus SARSCoV-2. Eur J Nucl Med Mol Imaging. 2020;47:1275-80.

5. Singh AK, Singh A, Shaikh A, Singh R, Misra A. Chloroquine and hydroxychloroquine in the treatment of COVID-19 with or without diabetes: a systematic search and a narrative review with a special reference to India and other developing countries. Diabetes Metab Syndr. 2020;14:241-6.

6. Tufan A, Avanoglu Guler A, Matucci-Cerinic M. COVID-19, immune system response, hyperinflammation and repurposing antirheumatic drugs. Turk J Med Sci. 2020;50:620-32.

7. Alanagreh L, Alzoughool F, Atoum M. The human coronavirus disease COVID-19: its origin, characteristics, and insights into potential drugs and its mechanisms. Pathogens. 2020;9(5):331.

8. Shen KL, Yang YH, Jiang RM, Wang TY, Zhao DC, Jiang Y, et al. Updated diagnosis, treatment and prevention of COVID-19 in children: experts' consensus statement (condensed version of the second edition). World J Pediatr. 2020;24:1-8.

9. Chen G, Wu D, Guo W, Cao Y, Huang D, Wang H, et al. Clinical and immunological features of severe and moderate coronavirus disease 2019. J Clin Investig. 2020;130:2620-9.

10. Chen N, Zhou M, Dong X, Qu J, Gong F, Han Y, et al. Epidemiological and clinical characteristics of 99 cases of 2019 novel coronavirus pneumonia in Wuhan, China: a descriptive study. Lancet. 2020;395:507-13.

11. Prete M, Favoino E, Catacchio G, Racanelli V, Perosa F. SARSCoV-2 inflammatory syndrome clinical features and rationale for immunological treatment. Int J Mol Sci. 2020;21(9):3377.

12. Huang C, Wang Y, Li X, Ren L, Zhao J, Hu Y, et al. Clinical features of patients infected with 2019 novel coronavirus in Wuhan, China. Lancet. 2020;395:497-506.

13. Qiu H, Wu J, Hong L, Luo Y, Song Q, Chen D. Clinical and epidemiological features of 36 children with coronavirus disease 2019 (COVID-19) in Zhejiang, China: an observational cohort study. Lancet Infect Dis. 2020. https://doi.org/10.1016/S14733099(20)30198-5.

14. Wang H, Li X, Li T, Zhang S, Wang L, Wu X, et al. The genetic sequence, origin, and diagnosis of SARS-CoV-2. Eur J Clin Microbiol Infect Dis. 2020. https://doi.org/10.1007/s10096-02003899-4.

15. Udugama B, Kadhiresan P, Kozlowski HN, Malekjahani A, Osborne M, Li VYC, et al. Diagnosing COVID-19: the disease and tools for detection. ACS Nano. 2020;14:3822-35.

16. Wan DY, Luo XY, Dong W, Zhang ZW. Current practice and potential strategy in diagnosing COVID-19. Eur Rev Med Pharmacol Sci. 2020;24(8):4548-53.

17. Wong HYF, Lam HYS, Fong AH, Leung ST, Chin TW, Lo CSY, et al. Frequency and distribution of chest radiographic findings in COVID-19 positive patients. Radiology. 2019. https://doi.org/10. 1148/radiol.2020201160.

18. Shi H, Han X, Jiang N, Cao Y, Alwalid O, Gu J, et al. Radiological findings from 81 patients with COVID-19 pneumonia in 
Wuhan, China: a descriptive study. Lancet Infect Dis. 2020;20:425-34.

19. Li B, Li X, Wang Y, Han Y, Wang C, Zhang G, et al. Diagnostic value and key features of computed tomography in Coronavirus Disease 2019. Emerg Microbes Infect. 2020;9:787-93.

20. Kermali M, Khalsa RK, Pillai K, Ismail Z, Harky A. The role of biomarkers in diagnosis of COVID-19: a systematic review. Life Sci. 2020. https://doi.org/10.1016/j.lfs.2020.117788.

21. Jose RJ, Manuel A. COVID-19 cytokine storm: the interplay between inflammation and coagulation. Lancet Respir Med. 2020. https://doi.org/10.1016/S2213-2600(20)30216-2.

22. Ye Q, Wang B, Mao J. The pathogenesis and treatment of the 'Cytokine Storm' in COVID-19. J Infect. 2020;80(6):607-13.

23. Liu B, Li M, Zhou Z, Guan X, Xiang Y. Can we use interleukin-6 (IL-6) blockade for coronavirus disease 2019 (COVID-19)-induced cytokine release syndrome (CRS)? J Autoimmun. 2020. https://doi.org/10.1016/j.jaut.2020.102452.

24. Colson P, Rolain JM, Lagier JC, Brouqui P, Raoult D. Chloroquine and hydroxychloroquine as available weapons to fight COVID-19. Int J Antimicrob Agents. 2020;55(4):105932. https:// doi.org/10.1016/j.ijantimicag.2020.105932.

25. Biot C, Daher W, Chavain N, Fandeur T, Khalife J, Dive D, et al. Design and synthesis of hydroxyferroquine derivatives with antimalarial and antiviral activities. J Med Chem. 2006;49:2845-9.

26. Tett SE, Cutler DJ, Day RO, Brown KF. Bioavailability of hydroxychloroquine tablets in healthy volunteers. Br J Clin Pharmacol. 1989;27:771-9.

27. Furst DE. Pharmacokinetics of hydroxychloroquine and chloroquine during treatment of rheumatic diseases. Lupus. 1996;5(Suppl 1):S11-5.

28. Cutler DJ, MacIntyre AC, Tett SE. Pharmacokinetics and cellular uptake of 4-aminoquinoline antimalarials. Agents Actions. 1988;24:142-57.

29. Minie M, Chopra G, Sethi G, Horst J, White G, Roy A, et al. CANDO and the infinite drug discovery frontier. Drug Discov Today. 2014;19:1353-63.

30. Conway DJ. Paths to a malaria vaccine illuminated by parasite genomics. Trends Genet. 2015;31(2):97-107.

31. Karunamoorthi K. Malaria vaccine: a future hope to curtail the global malaria burden. Int J Prev Med. 2014;5(5):529-38.

32. de Beer TA, Wells GA, Burger PB, Joubert F, Marechal E, Birkholtz L, et al. Antimalarial drug discovery: in silico structural biology and rational drug design. Infect Disord Drug Targets. 2009;9(3):304-18.

33. Vedadi M, Lew J, Artz J, Amani M, Zhao Y, Dong A, et al. Genome-scale protein expression and structural biology of Plasmodium falciparum and related Apicomplexan organisms. Mol Biochem Parasitol. 2007;151(1):100-10.

34. Flannery EL, Chatterjee AK, Winzeler EA. Antimalarial drug discovery: approaches and progress towards new medicines. Nat Rev Microbiol. 2017;11:849-62.

35. Ridley RG. Medical need, scientific opportunity and the drive for antimalarial drugs. Nature. 2002;415:686-93.

36. Mitchell W. Natural products from synthetic biology. Curr Opin Chem Biol. 2011;15:505-15.

37. Paddon CJ, Westfall PJ, Pitera DJ, Benjamin K, Fisher K, McPhee D, et al. High-level semisynthetic production of the potent antimalarial artemisinin. Nature. 2013;496(7446):528-32.

38. Buckee CO, Wesolowski A, Eagle NN, Hansen E, Snow RW. Mobile phones and malaria: modeling human and parasite travel. Travel Med Infect Dis. 2013;11:15-22.

39. Hay SI, George DB, Moyes CL, Brownstein JS. Big data opportunities for global infectious disease surveillance. PLoS Med. 2013;10:e1001413.
40. Pahan P, Pahan K. Smooth or risky revisit of an old malaria drug for COVID-19? J Neuroimmune Pharmacol. 2020. https://doi. org/10.1007/s11481-020-09923-w.

41. Dorner T. Crossroads of $B$ cell activation in autoimmunity: rationale of targeting B cells. J Rheumatol. 2006;77:3-11.

42. Kuznik A, Bencina M, Svajger U, Jeras M, Rozman B, Jerala R. Mechanism of endosomal TLR inhibition by antimalarial drugs and imidazoquinolines. J Immunol. 2011;186:4794-804.

43. Ireland JM, Unanue ER. Autophagy in antigen-presenting cells results in presentation of citrullinated peptides to CD4 T cells. J Exp Med. 2011;208(13):2625-32.

44. Raoult D, Drancourt M, Vestris G. Bactericidal effect of doxycycline associated with lysosomotropic agents on Coxiella burnetii in P388D1 cells. Antimicrob Agents Chemother. 1990;34(8):1512-4.

45. Qushmaq NA, Al-Emadi SA. Review on effectiveness of primary prophylaxis in aPLs with and without risk factors for thrombosis: efficacy and safety. ISRN Rheumatol. 2014. https://doi.org/10. 1155/2014/348726.

46. Jancinova V, Nosal R, Petrikova M. On the inhibitory effect of chloroquine on blood platelet aggregation. Thromb Res. 1994;74(5):495-504.

47. Nosal R, Jancinova V, Petrikova M. Chloroquine inhibits stimulated platelets at the arachidonic acid pathway. Thromb Res. 1995;77(6):531-42.

48. Rand JH, Wu XX, Quinn AS, Chen PP, Hathcock JJ, Taatjes DJ. Hydroxychloroquine directly reduces the binding of antiphospholipid antibody-beta2-glycoprotein I complexes to phospholipid bilayers. Blood. 2008;112(5):1687-95.

49. Izmirly PM, Costedoat-Chalumeau N, Pisoni CN, Khamashta MA, Kim MY, Saxena A, et al. Maternal use of hydroxychloroquine is associated with a reduced risk of recurrent antiSSA/Ro-antibody-associated cardiac manifestations of neonatal lupus. Circulation. 2012;126(1):76-82.

50. Saxena A, Izmirly PM, Mendez B, Buyon JP, Friedman DM. Prevention and treatment in utero of autoimmune-associated congenital heart block. Cardiol Rev. 2014;22(6):263-7.

51. Lisney AR, Szelinski F, Reiter K, Burmester GR, Rose T, Dorner T. High maternal expression of SIGLEC1 on monocytes as a surrogate marker of a type I interferon signature is a risk factor for the development of autoimmune congenital heart block. Ann Rheum Dis. 2017;76(8):1476-80.

52. Carmichael SJ, Beal J, Day RO, Tett SE. Combination therapy with methotrexate and hydroxychloroquine for rheumatoid arthritis increases exposure to methotrexate. J Rheumatol. 2002;29(10):2077-83

53. Munster T, Gibbs JP, Shen D, Baethge BA, Botstein GR, Caldwell $\mathrm{J}$, et al. Hydroxychloroquine concentration-response relationships in patients with rheumatoid arthritis. Arthritis Rheum. 2002;46(6):1460-9.

54. Somer M, Kallio J, Pesonen U, Pyykko K, Huupponen R, Scheinin M. Influence of hydroxychloroquine on the bioavailability of oral metoprolol. $\mathrm{Br} \mathrm{J}$ Clin Pharmacol. 2000;49(6):549-54.

55. Bannwarth B, Pehourcq F, Schaeverbeke T, Dehais J. Clinical pharmacokinetics of low-dose pulse methotrexate in rheumatoid arthritis. Clin Pharmacokinet. 1996;30(3):194-210.

56. Kormelink TG, Tekstra J, Thurlings RM, Boumans MH, Vos K, Tak PP, et al. Decrease in immunoglobulin free light chains in patients with rheumatoid arthritis upon rituximab (anti-CD20) treatment correlates with decrease in disease activity. Ann Rheum Dis. 2010;69(12):2137-44.

57. Chatre C, Roubille F, Vernhet H, Jorgensen C, Pers YM. Cardiac complications attributed to chloroquine and hydroxychloroquine: a systematic review of the literature. Drug Saf. 2018;41(10):919-31. 
58. Toimela T, Tahti H, Salminen L. Retinal pigment epithelium cell culture as a model for evaluation of the toxicity of tamoxifen and chloroquine. Ophthalmic Res. 1995;27(Suppl 1):150-3.

59. Srinivasa A, Tosounidou S, Gordon C. Increased incidence of gastrointestinal side effects in patients taking hydroxychloroquine: a brand-related issue? J Rheumatol. 2017;44(3):398.

60. Dogar MU, Shah NN, Ishtiaq S, Shah PN, Shah P, Mathew S, Vittorio TJ. Hydroxychloroquine-induced restrictive cardiomyopathy: a case report. Postgrad Med J. 2018;94(1109):185-6.

61. Touret F, de Lamballerie X. Of chloroquine and COVID-19. Antivir Res. 2020;177:104762. https://doi.org/10.1016/j.antiviral. 2020.104762.

62. Ferner RE, Aronson JK. Chloroquine and hydroxychloroquine in covid-19. BMJ. 2020;369:m1432. https://doi.org/10.1136/bmj. m1432.

63. Li M, Ramos LG. Drug-induced QT prolongation and torsades de pointes. P T. 2017;42(7):473-7.

64. Saleh M, Gabriels J, Chang D, Kim BS, Mansoor A, Mahmood E, et al. The effect of chloroquine, hydroxychloroquine and azithromycin on the corrected QT Interval In Patients with SARSCoV-2 infection. Circ Arrhythm Electrophysiol. 2020. https://doi. org/10.1161/CIRCEP.120.008662.

65. Mehra MR, Desai SS, Ruschitzka F, Patel AN. Hydroxychloroquine or chloroquine with or without a macrolide for treatment of COVID-19: a multinational registry analysis. Lancet. 2020. https://doi.org/10.1016/S0140-6736(20)31180-6.
66. Helms J, Tacquard C, Severac F, Leonard-Lorant I, Ohana M, Delabranche $\mathrm{X}$, et al. High risk of thrombosis in patients with severe SARS-CoV-2 infection: a multicenter prospective cohort study. Intensive Care Med. 2020. https://doi.org/10.1007/s00134020-06062-x.

67. Ranucci M, Ballotta A, Di Dedda U, Bayshnikova E, Dei Poli M, Resta M, et al. The procoagulant pattern of patients with COVID19 acute respiratory distress syndrome. J Thromb Haemost. 2020. https://doi.org/10.1111/jth.14854.

68. Bertrand E, Cloitre B, Ticolat R, Bile RK, Gautier C, Abiyou GO, Bohui BY. Antiaggregation action of chloroquine. Med Trop (Mars). 1990;50(1):143-6.

69. Edwards MH, Pierangeli S, Liu X, Barker JH, Anderson G, Harris EN. Hydroxychloroquine reverses thrombogenic properties of antiphospholipid antibodies in mice. Circulation. 1997;96(12):4380-4.

70. Miranda S, Billoir P, Damian L, Thiebaut PA, Schapman D, Le Besnerais $\mathrm{M}$, et al. Hydroxychloroquinereverses the prothrombotic state in a mouse model of antiphospholipid syndrome: role of reduced inflammation and endothelial dysfunction. PLoS ONE. 2019;14(3):e0212614.

Publisher's Note Springer Nature remains neutral with regard to jurisdictional claims in published maps and institutional affiliations. 